\title{
Hybrid Bilateral Advance Pricing Agreements: The Trend for the Future?
}

\author{
Toshiaki Katsushima, Deloitte \& Touche Tohmatsu, Tokyo
}

As the NTA and the IRS continue to negotiate bilateral Advance Pricing Agreements (APAs), it appears that supply is not keeping up with demand, which has increased significantly in response to stepped-up transfer pricing enforcement action by the NTA and the IRS. One source of delay in this regard is the difficult job of negotiating a compromise on conflicting transactional pricing methodologies. The NTA is not willing to proceed where the methodology used is the comparable profit method (CPM). Generally, the NTA believes that CPM is not an arm's-length method to the extent that it requires a loss company to ignore its loss and price its goods in order to provide an affiliate with profits earned by comparables which reflect transactions entered into with profitable entities, among other issues. Given this position and the IRS' preference for CPM, it would appear that a hybrid method is required to account for the differing viewpoints of the IRS and NTA.

Earlier this year, the NTA and the IRS reached an agreement to grant an APA to a Komatsu, for the first time using a hybrid profit-split/CPM methodology. This approach has some appeal, since it appears reasonable and practical. From a Japanese perspective, the hybrid methodology has an advantage, in that profit-split allows for detailed analysis of a company's business activities and operational results of the taxpayer's business, whereas CPM uses only publicly available data. It also appears that the fact that the hybrid compromise was leaked to the press is a sign by both the Japanese and US governments that they are receptive to breaking the impasse as well as other creative uses of existing APA methods.

It is interesting that, based on informal discussions with NTA officials, the use of a hybrid method is not viewed as representing a change in its policy in transfer pricing methodology, as it has indicated that the perceived use of a combined method is due to the fact that the acceptable ranges under CPM and profit-split overlapped. However, this could be an indication that the NTA can be flexible and is willing to focus on the bottom line, rather than on theoretical principles of transfer pricing methodology themselves. It is this more flexible attitude which will be a key as we progress with resolving transfer pricing cases.

Perhaps the flexibility employed by the US and Japanese competent authorities in creating the hybrid methodology will lead to increased settlements of transfer pricing cases and APA applications currently in competent authority negotiation. Hopefully, there will be other cases where resolution will be effected using a hybrid method as employed the Komatsu case. Based on our knowledge of the details of the Komatsu case and the methodology involved, it might serve as a model for achieving USA-Japan bilateral APAs, at least where the facts are similar to those of the Komatsu case. At the very least, we may see many different types of hybrid profit-split methodologies developing on a case-by-case basis because of the recent flexibility of the NTA and IRS in approaching bilateral APAs.

In the meantime, it will be a challenge to find other ways to combine CPM and the profit-split method. From a Japanese perspective, there will be many questions on how to apply profit-split in complicated situations, such as integrated manufacturing, through Asia and companies with significant research and development or other intangibles.

Where does this leave us? It's hard to say with any certainty, but the Komatsu hybrid methodology represents a good start for dealing with the different viewpoints of the IRS and the NTA. The relationship between the NTA and the IRS has improved radically from that of over just a year ago, where the IRS insisted on CPM, and the NTA on profitsplit. This kind of flexibility is healthy, and we should expect other types of hybrid methodologies in the future. 